\title{
Application Security Problem
}

National Cancer Institute

\section{Source}

National Cancer Institute. Application Security Problem. NCI Thesaurus. Code C63042.

Problem associated with the acquisition of computer programming codes that can replicate and spread from one computer system to another thereby leading to damaged software, hardware and data. 